\title{
Can Anxiety Tested in the Elevated Plus-maze Be Related to Nociception Sensitivity in Adult Male Rats?
}

\section{Marie Pometlová, Anna Yamamotová, Kateryna Nohejlová, Romana Šlamberová}

Department of Normal, Pathological and Clinical Physiology, Third Faculty of Medicine, Charles University, Prague, Czech Republic

Received October 19, 2016; Accepted November 21, 2016.

Key words: Drug abuse - Prenatal exposure - Methamphetamine - Anxiety - Nociception - Elevated plus-maze - Plantar test

Abstract: Methamphetamine (MA) is one of the most addictive psychostimulant drugs with a high potential for abuse. Our previous studies demonstrated that MA administered to pregnant rats increases pain sensitivity and anxiety in their adult offspring and makes them more sensitive to acute administration of the same drug in adulthood. Because individuals can differ considerably in terms of behaviour and physiology, such as rats that do not belong in some characteristics (e.g. anxiety) to average, can be described as low-responders or high-responders, are then more or less sensitive to pain. Therefore, prenatally MA-exposed adult male rats treated in adulthood with a single dose of $M A(1 \mathrm{mg} / \mathrm{ml} / \mathrm{kg})$ or saline $(1 \mathrm{ml} / \mathrm{kg})$ were tested in the present study. We examined the effect of acute MA treatment on:

(1) the anxiety in the Elevated plus-maze (EPM) test and memory in EPM re-test;

(2) nociception sensitivity in the Plantar test; (3) the correlation between the anxiety, memory and the nociception. Our results demonstrate that: (1) MA has an anxiogenic effect on animals prenatally exposed to the same drug in the EPM; (2) all the differences induced by acute MA treatment disappeared within the time of 48 hours; (3) there was no effect of MA on nociception per se, but MA induced

This study was supported by grant \# 14-03708S from the Grant Agency of the Czech Republic, projects \# PRVOUK P34, GAUK 706216 and 260277/SVV/2016 from Charles University, and project \# NT/14484 from the Internal Grant Agency of the Ministry of Health of the Czech Republic.

Mailing Address: Prof. Romana Šlamberová, MD., PhD., Department of Normal, Pathological and Clinical Physiology, Third Faculty of Medicine, Charles University, Ke Karlovu 4, 12000 Prague 2, Czech Republic; Phone: +420 224902 713; Fax: +420 224902 750; e-mail: romana.slamberova@If3.cuni.cz 
higher anxiety in individuals less sensitive to pain than in animals more sensitive to pain. In conclusion, the present study demonstrates unique data showing association between anxiety and nociceptive sensitivity of prenatally MA-exposed rats that is induced by acute drug administration.

\section{Introduction}

Methamphetamine (MA) is one of the most addictive psychostimulant drug with a high potential for abuse. It is also one of the most frequently used "hard" drug in the Czech Republic (Vavřínková et al., 2001) and due to its anorectic effects, it is one of the most commonly abused drug among women, even during pregnancy (Marwick, 2000). Our previous studies demonstrated that MA administered to pregnant rats increases pain sensitivity in their offspring in adulthood (Yamamotová et al., 2011). In addition, our recent study (Šlamberová et al., 2015) demonstrated that prenatal MA exposure increases anxiety of adult male rats and makes them more sensitive to acute administration of the same drug in adulthood.

In addition, there are studies showing that administration of MA in adulthood improves cognitive processes (Kornetsky et al., 1959), does not have any effects on cognition (Fialová et al., 2015), or impairs the learning abilities of adult male rats (Meredith et al., 2005; Schutová et al., 2009). This inconsistency seems to be caused by different dose of the drug, duration of the drug exposure and the type of cognition test used in the studies (Simoes et al., 2007; Belcher et al., 2008). Our previous study demonstrated that the effect of MA administration in adulthood on cognition is influenced by prenatal MA exposure, which seems to correlate with NMDA (N-methyl-D-aspartate) receptors in the hippocampus (Šlamberová et al., 2014).

As show in the study of Borta and Schwarting (2005) rats, although identical in strain, sex, age and housing conditions, can differ considerably in terms of behaviour and physiology. Such individual differences can be rather stable and may be detected by behavioural screening tests. There are studies showing that animals that do not belong in some characteristics (e.g. anxiety) to average (the most often incidence), but can be described as low-responders or high-responders, are then more or less sensitive to pain (Ho et al., 2002).

Studies of Rodgers and Dalvi (1997) and Rodgers et al. (1999) found that exposure to the Elevated plus-maze (EPM) test induces behavioural and physiological effects in rodents consistent with fear/anxiety. Maze-naive animals displayed high levels of risk assessment towards the open arms, and explore these areas less extensively than other parts of the maze. Immediately following the EPM test, pain latencies (Rodgers and Cole, 1994), skin conductance levels (Suer et al., 1998), and plasma corticosterone titers were shown to be significantly elevated (Rodgers et al., 1999). Also clinical studies (Lautenbacher and Krieg, 1994; Asmundson and Katz, 2009; Bras et al., 2010) repeatedly showed that anxiety decreases threshold of nociception, thereby increases pain sensitivity. Therefore, 
the present study was set to examine possible correlations between the effects of MA on pain sensitivity and anxiety. To test anxiety EPM test was chosen as the most appropriate test of anxiety (Pometlová et al., 2009). For pain sensitivity the Plantar test was used as in our previous studies (Yamamotová et al., 2011).

Moreover, the experiment was expanded for the influence on learning and memory in accordance with the protocol "test/re-test" in the EPM (Carobrez and Bertoglio, 2005). After exploring the maze during the first testing the rat saves the information that the area is not dangerous, in that part of memory that relates to exploration of potentially dangerous areas, and the rat changes its behaviour during the retest. If the drug disrupts learning process, the pattern of behaviour is changed in comparison with the first test (File, 1993; Bertoglio and Carobrez, 2002; Bertoglio et al., 2005). Based on our previous results (Schutová et al., 2009) we assume that the influence on the consolidation of the memory trace will be not significant.

\section{Methods}

The procedures for animal experimentation in this study were reviewed and approved by the Institutional Animal Care and Use Committee and were in agreement with the Czech Government Requirements under the Policy of Human Care of Laboratory Animals (No. 246/1992) and with subsequent regulations from the Ministry of Agriculture of the Czech Republic.

Animals and prenatal care

Adult female (275-300 g) and male (375-400 g) albino Wistar rats provided by Charles River Laboratories International, Inc., were delivered by AnLab (Prague, the Czech Republic). Animals were housed four per cage by sex and left undisturbed for a week in a temperature-controlled $\left(22-24^{\circ} \mathrm{C}\right)$ colony room with free access to food and water on a $12 \mathrm{~h}$ (light):12 h (dark) cycle with lights on at 06:00 h. Eight females were impregnated as described in our previous study (Šlamberová et al., 2005). On gestational day (GD) 1 the daily injections of MA started and continued until the day of delivery, which usually occurred on GD 22. D-methamphetamine $\mathrm{HCl}$ (Sigma Aldrich, the Czech Republic) was diluted in distilled water in concentration of $5 \mathrm{mg} / \mathrm{ml}$ and injected subcutaneously (s.c.) in a volume of $1 \mathrm{ml} / \mathrm{kg}$. The dose $5 \mathrm{mg} / \mathrm{kg}$ of MA was chosen because it induces similar fetal brain drug concentrations and similar behavioural changes to those found in humans (Acuff-Smith et al., 1996; Rambousek et al., 2014).

The day of the delivery was indexed as postnatal day (PD) 0. On PD 1, pups were weighed and the number of pups was adjusted to 12 per litter. Whenever possible, the number of male and female pups raised by a dam was equal. On PD 21, pups were weaned and group-housed by sex. Animals were left undisturbed until adulthood. In order to avoid litter effects, only two male rat from each litter was used in the present study (one for each adult injection). The rest of the animals were used in other experiments. 
Schedule of the experiment

In total 16 adult male rats (PD 80-90) prenatally exposed to MA were tested in this experiment ( $n=8$ rats/group). All of the animals were handled according to the protocol described in Behavioral Science Protocols (Geyer and Swerdlow, 2007) during three days prior to the EPM tests.

After the three days of handling, animals were tested in the EPM. Forty-five minutes prior to testing, animals were injected with either a challenge dose of MA $(1 \mathrm{mg} / \mathrm{ml} / \mathrm{kg})$ or saline $(1 \mathrm{ml} / \mathrm{kg})$. The dose of MA was chosen based on our previous studies (Šlamberová et al., 2010; Schutová et al., 2013) showing that this dose does not induce stereotypical behaviours. The timing of the drug application was chosen based on the study of Rambousek et al. (2014) demonstrating that the peak of MA level in the brain (not in the blood) occurred between the $45^{\text {th }}$ and $60^{\text {th }}$ minute after administration.

To see the effect of MA on learning, the EPM experiment was further expanded for the protocol of "test/re-test" as shown in the study of Carobrez and Bertoglio (2005). In details, forty-eight hours after the EPM test, animals retook the test on the EPM (re-test) but without any drug administration. Directly after the re-test on the EPM animals were examined for nociception sensitivity in the Plantar test (see time-line at Figure 1).

\section{Elevated plus-maze (EPM)}

The same method was used as in our previous study (Pometlová et al., 2012), which was a modified protocol of Fernández Espejo (1997). All animals were habituated to the laboratory environment and the experimenter during the 3 days prior to the experiment (Geyer and Swerdlow, 2007). At the beginning of the test an animal was positioned on the center square of plus maze with the animal's nose pointing toward one of the closed arms (CA). Animal behaviour in the EPM was video-recorded for five minutes. Acquired video records were evaluated using the ODLog program (Macropod Software ${ }^{\mathrm{TM}}$ ). Animal behaviour was divided into four categories as follows.

The first category included behaviour related to anxiety. The anxiolytic effect on animal behaviour was described as activities in open arms (OA): the number

\begin{tabular}{|c|c|c|c|c|c|c|c|}
\hline $\begin{array}{c}\text { Prenatal } \\
\text { MA } \\
\text { exposure }\end{array}$ & $\begin{array}{c}\text { Postnatal } \\
\text { development } \\
\text { (no distur- } \\
\text { bance) }\end{array}$ & $\begin{array}{c}3 \text { days } \\
\text { of habi- } \\
\text { tuation }\end{array}$ & $\begin{array}{c}\text { MA or } \\
\text { saline s.c. } \\
\text { application }\end{array}$ & $\begin{array}{c}\text { EPM test } \\
45 \text { min } \\
\text { after } \\
\text { injection }\end{array}$ & $\begin{array}{c}48-h \\
\text { break } \\
\text { period }\end{array}$ & $\begin{array}{c}\text { EPM } \\
\text { re-test }\end{array}$ & $\begin{array}{c}\text { Plantar } \\
\text { test }\end{array}$ \\
\hline ED 1-22 & PD 1-60 & $\begin{array}{c}\text { Test } \\
\text { day 1-3 }\end{array}$ & \multicolumn{2}{|c|}{ Test day 4} & $\begin{array}{c}\text { Test } \\
\text { day 5 }\end{array}$ & Test day 6 \\
\hline
\end{tabular}

Figure 1 - Time-line of the experiment. 
of entries to the $O A$ and total time spent there. Anxiogenic effect on animal behaviour involved activities in the CA and the center: the number of entries to the CA and total time spent there, the number of protected head-dipping (DIP) and protected stretched attend postures (SAP) (Fernández Espejo, 1997). DIP was defined as head-dipping below surface of the maze that occurred on the center square, while the body of an animal remained in the CA or central platform. SAP was defined as forward elongation of head and shoulders followed by retraction to initial position. In this study it was recorded when it occurred on the central platform, while the body and all paws of an animal remained in the CA.

The second category described approach-avoidance conflict and also depicted types of behaviour with respect to OA and CA, i.e., positioning of an animal with all four paws in the center of the maze followed by retrieval (meaning moving backwards) to the CA.

The third behavioural category in the EPM was used to describe motor activity. Evaluated activities included the total number of entrances into all arms and sniffing in the center of the EPM (mobile or quiet olfactory exploration of the environment).

The last category included displacement behaviour as a measure of anxiety, i.e., self-grooming, etc. This category was not evaluated because at a dose of $1 \mathrm{mg} / \mathrm{kg}$ it did not occur.

Frequency of specific behavioural patterns as well as time spent engaged in specific behaviours were used for statistical analyses.

\section{Plantar test}

The same method was used as in our previous study (Yamamotová et al., 2011). Plantar test (Plantar test; Ugo Basile, Comerio, Italy) was used to measure nociceptive sensitivity. A beam generator, which is controlled by the experimenter under the floor of the Plexiglas box (size $27 \times 17 \times 14 \mathrm{~cm}$ ) allows to stimulate the sole (planta) of the paw in a freely moving rat. The latency of paw withdrawal from painful heat stimulus was measured for each of the four paws. Latency to withdrawal of the tail was measured as a modified method of the tail-flick test. The stimulation was repeated four times. Each repetition progressed from more distal to more proximal parts of the tail. The inter-stimulus intervals ranged from $1 / 2$ to $1 \mathrm{~min}$ in order to let the animals calm down from the preceding stimulus. The maximal intensity was set to 90 and cut-off time was $22 \mathrm{~s}$ to prevent tissue damage.

\section{Statistical analyses}

A one-way ANOVA (MA vs. saline) with repeated measure (test vs. re-test) was used for statistical analyses of the results of the EPM test and re-test. Bonferroni post-hoc test was used when appropriate. In the Plantar test, the factor treatment (MA vs. saline) comprised the between-subject variable. The within-subject variables 
(factor pain) consisted of three measured body sites (average withdrawal latency of forelimb, hind limb and the tail).

An association between pain sensitivity and anxiety was analysed using correlation technique. As the data from EPM were not normally distributed Spearman rank order correlation was applied.

Differences were considered significant if $\mathrm{p}<0.05$.

All statistical data in this report are presented as $[F(N-1, n-N)=x x . x x ; p<0.0 x]$, where $\mathrm{F}=$ test criterion of ANOVA, N-1 = degrees of freedom of groups, $n-N=$ degrees of freedom of individual subjects, $p=$ probability level.

\section{Results}

Elevated plus-maze test

Concerning the anxiogenic/anxiolytic effect, there were no significant differences in the measure of entries and time spent in the OA (anxiolytic effect), nor in the CA (anxiogenic effect) of the EPM apparatus (Table 1). However, when more detailed analysis was conducted, animals injected with MA displayed decreased DIP $[F(1,14)=5.58 ; p<0.01]$ and increased SAP $[F(1,14)=6.40 ; p<0.01]$ during the EPM test relative to saline controls (Figure 2).

The approach-avoidance conflict was significantly changed by the MA administration in the EPM test $[F(1,14)=8.46 ; p<0.01]$, thereby that $M A$ administration increase the number of returns to the CA when compared to saline-treated animals in the EPM (Figure 2).

The motor activity that was evaluated as number of entries to all arms and frequency as well as time spent with sniffing was not significantly affected by MA administration (Table 1).

Table 1 - Nonsignificant effects on behaviour in the EPM

\begin{tabular}{lcccc}
\hline & \multicolumn{2}{c}{ Test } & \multicolumn{2}{c}{ Re-test } \\
\cline { 2 - 5 } & \multicolumn{1}{c}{ Saline } & MA & Saline & MA \\
\hline OA entries & $1.88 \pm 1.05$ & $1.50 \pm 1.04$ & $0.88 \pm 0.45$ & $0.50 \pm 0.48$ \\
OA time (s) & $24.50 \pm 12.92$ & $19.38 \pm 12.91$ & $13.88 \pm 6.30$ & $5.13 \pm 6.25$ \\
CA entries & $14.13 \pm 1.83$ & $20.00 \pm 1.84$ & $9.25 \pm 1.93$ & $10.75 \pm 1.94$ \\
CA time (s) & $132.63 \pm 17.15$ & $143.88 \pm 17.15$ & $162.00 \pm 20.90$ & $202.50 \pm 20.91$ \\
Locomotion & $8.88 \pm 1.97$ & $10.00 \pm 1.97$ & $4.13 \pm 1.46$ & $3.25 \pm 1.45$ \\
(arms entries) & & & & \\
Sniffing frequency & $15.75 \pm 2.05$ & $19.13 \pm 2.06$ & $11.00 \pm 2.29$ & $9.75 \pm 2.28$ \\
Sniffing time (s) & $76.38 \pm 9.99$ & $77.00 \pm 10.00$ & $89.88 \pm 13.13$ & $53.88 \pm 13.12$ \\
\hline
\end{tabular}

Numbers are means \pm SEM ( $n=8)$; EPM - elevated plus-maze; MA - methamphetamine; OA - open arms; $\mathrm{CA}$ - closed arms 

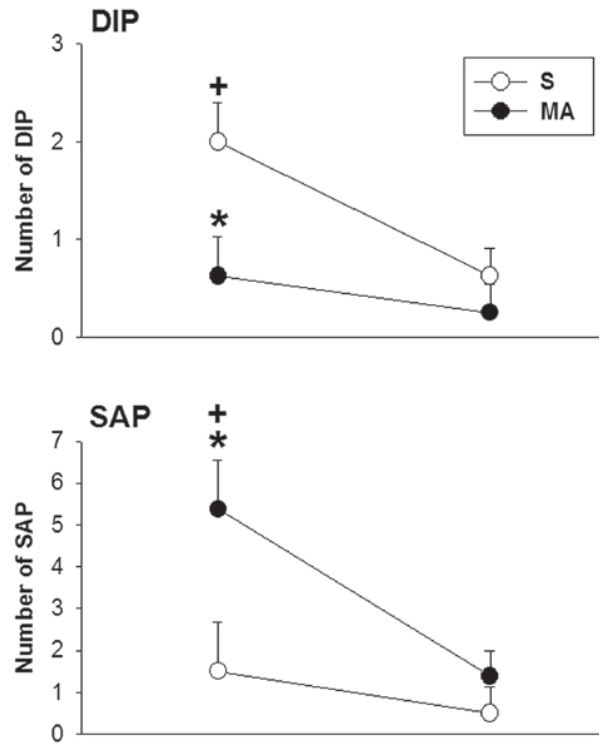

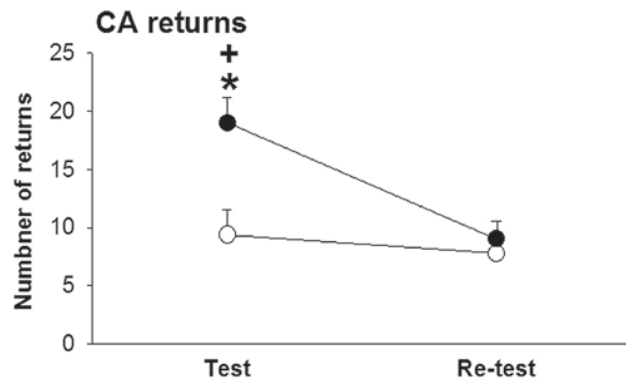

Figure 2 - Effect of MA administration on anxiogenic behaviour in the EPM test. DIP = protected headdipping, $S A P=$ protected stretched attend postures, $C A$ returns $=$ returns to the closed arms (measure of approach-avoid conflict). Numbers are means \pm SEM $(n=8) .{ }^{*} p<0.01$ vs. saline-treated animals during the $E P M$ test. $+p<0.01$ vs. animals tested in EPM during the re-test.

\section{Elevated plus-maze re-test}

As shown in Figure 2, there were no differences induced by acute MA administration on DIP, SAP and returns to the CA as shown in the EPM test.

\section{Plantar test}

The withdrawal latencies on thermal stimulation were measured after the re-test in the EPM. Neither MA nor saline application influenced nociceptive sensitivity (main effect of treatment $[F(1,14)=2.13 ; p=0.17])$. Pain sensitivity measured on different

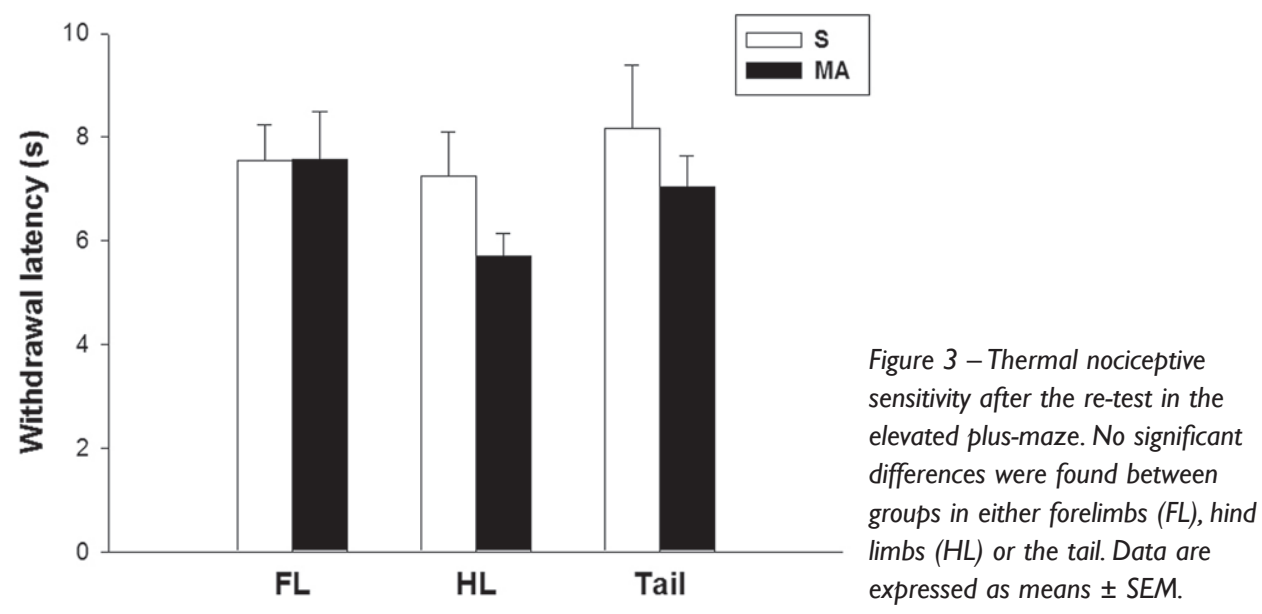

Methamphetamine, Anxiety and Nociception 
body parts was also similar (main effect of factor pain $[F(2,28)=1.09 ; \mathrm{p}=0.35]$ ). Interaction of factors treatment and pain was also nonsignificant $[F(2,28)=0.46$; $p=0.64$ ] (Figure 3).

\section{Correlations}

From correlation matrices evaluating pain sensitivity in relation to measured parameters from EPM follows that significant results were obtained only for those animals that were formerly treated with MA. More specifically, after application of $M A$, animals with lower pain threshold on the tail spent more time in $O A[r=-0.71$; $p=0.048]$, more frequently visited $O A[r=-0.74 ; p=0.036]$, generally spent more time in $\mathrm{OA}$ in relation to $\mathrm{CA}[\mathrm{r}=-0.71 ; \mathrm{p}=0.048]$, and average single visit in $\mathrm{CA}$ was shorter $[r=0.86 ; p=0.006]$ (Figure 4). No significant correlations were found in animals previously treated with saline.

\section{Discussion}

Our results can be presented in three steps. First, the anxiety data from the EPM test and memory in re-test. Second, the results showing changes in nociception tested in the Plantar test. Third, the correlation between the anxiety, memory and the nociception.

First, our data from the EPM test did not show any robust changes induced by application of MA (no effect on entries and time spend in the open/closed

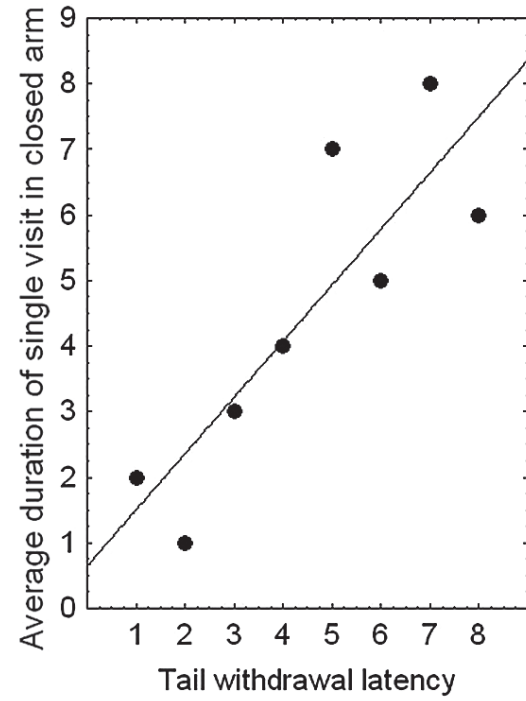

MA

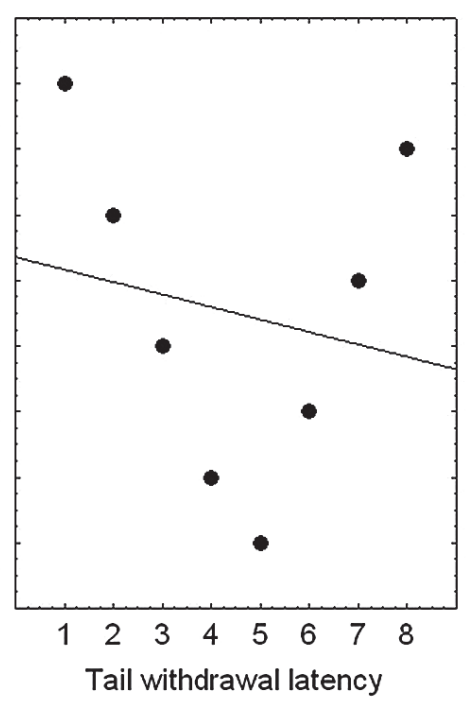

$\mathrm{s}$

Figure 4 - Rank-order correlation between the tail withdrawal latency on thermal stimulus measured after retest in EPM and the average duration of single visit in closed arms of the EPM after injection of MA or saline. Anxiogenic effect of MA was observed in animals with longer withdrawal latencies $(r=0.8571 ; p=0.0065)$. 
arms). However, our detailed analysis based on studies of Fernández Espejo (1997) and Pometlová et al. (2009) suggests rather anxiogenic effect of acute MA administration, such as increased number of SAP as well as number of CA returns. This is in agreement with our recent study showing anxiogenic effect of prenatal and acute MA exposure in different models of anxiety (Šlamberová et al., 2015). The only disputatious might be our finding showing decreased number of DIP after acute MA administration. Decreased of DIP is by Fernández Espejo (1997) interpreted as anxiolytic behaviour. Based on our results, however, one may offer different interpretation of these data. Note that DIP is defined as headdipping below surface of the maze that occurred on the center square, while the body of an animal remained in the closed arm or central platform. It is possible that increase of such a behaviour means that these animals are more adventurous and are not afraid of heights so much. This is however only our speculation.

In addition to these findings, re-test in the EPM was conducted 48 hours after the first anxiety testing to test learning ability. Shortly we can say that all the differences between acute MA- and saline-treated groups disappeared within the time of 48 hours. Specifically, the effect of acute MA administration decreased with the time between test and re-test in the number of SAP and number of CA returns. In contrast, there was significant decrease of the number of DIP in saline-treated group, but no change in MA-treated group. This confirms ambiguous effect of acute MA, because after 48 hours the animals are both the same. It should be noted the EPM is a model of "state" anxiety that tests unconditioned responses (Belzung and Griebel, 2001). There are many factors that may affect the performance of the EPM test, such as strain, sex, age and housing conditions (Borta and Schwarting, 2005). Influence of acute administration of MA was not manifested, which is in agreement with our previous Morris water maze study (Schutová et al., 2009).

Second, our data show no differences in nociceptive sensitivity between MAand saline-treated groups. Our previous studies (Yamamotová et al., 2004, 2011; Hrubá et al., 2010b; Yamamotová and Šlamberová, 2012) consistently showed that prenatal treatment of pregnant mothers with MA has long-term impact on nociception in their offspring. Even in adulthood these animals have decreased pain thresholds contrary to control animals. Although the mechanism underlying the increased pain perception induced by prenatal exposure to MA is not clear at present, during early stages of development prenatal MA may sensitize nociceptive system via up-regulation of the NMDA receptors activity which then cause an increase in the pain perception due to changes in central excitability (Šlamberová et al., 2009, 2014; Chen et al., 2010; Hrubá et al., 2010a; Vrajová et al., 2014).

After EPM re-test, the groups did not differ in nociceptive sensitivity. Given that both groups were exposed during the prenatal period to MA, there was no reason to assume that they will differ in this respect. From this point of view, we 
can assume that the observed reaction to pain is specific characteristic of the individual.

Third, it was shown that chronic pain can lead to anxiety and anxiety can enhance pain (Koga et al., 2015). However, anxiety can exacerbate pain perception when the source of anxiety is related to the pain experience. When the source is related to something else, anxiety may even reduce the reaction to pain (Weisenberg et al., 1984). Classification of Wistar rats into high and low anxious animals according their behaviour in the EPM showed that despite their different basal levels of trait anxiety, rats did not exhibit different levels of mechanical hypersensitivity (Wilson et al., 2007). Contrary to these results, an increase of heat pain threshold was observed in high anxious rats compared to normal Wistar rats (Jochum et al., 2007).

In addition, our results demonstrated that in the re-test, the groups did not differ in the length of stay and frequency of visits in open and closed arms of the EPM. No relationships were further found between measured characteristics in the EPM and nociception. On the other hand, significant correlations were found between anxiety after application of MA and nociceptive sensitivity measured two days later. It can be interpreted as follows; assuming relatively stable patter in nociception, acute dose of MA had a greater anxiolytic effect in individuals more sensitive to pain than in animals less sensitive to pain and the other way around. A similar relationship between nociception and anxiety was observed in rats after administration of $\mathrm{N}$-feruloylserotonin (extracted from Leuzea carthamoides) which has been demonstrated anxiolytic effect (Yamamotová et al., 2007).

There are several studies showing that anxiety in the EPM induces analgesia of non-opioid type. In mice, 5-min exposure to the EPM induced a mild, though enduring, elevation in tail-flick latencies and pre-treatments with the opiate antagonist naltrexone failed to block EPM-induced antinociception (Lee and Rodgers, 1990). In rats, the results shown that open EPM-induced antinociception did not display cross-tolerance to morphine and failed to be reversed by naltrexone (Cornelio and Nunes-de-Souza, 2009). Therefore, our animals with higher pain thresholds can be considered more anxious/stressed and the effect of MA might be therefore more anxiogenic, unlike less stressed animals, in which MA might be more anxiolytic.

We can summarize the present data the following way: first, MA has an anxiogenic effect on animals prenatally exposed to the same drug in the EPM; second, all the differences induced by acute MA treatment disappeared within the time of 48 hours; third, there was no effect of MA on nociception per se, but MA induced higher anxiety in individuals less sensitive to pain than in animals more sensitive to pain. To conclude, the present study demonstrates unique data showing association between anxiety and nociceptive sensitivity of prenatally MA-exposed rats that is induced by acute drug administration. 


\section{References}

Acuff-Smith, K. D., Schilling, M. A., Fisher, J. E., Vorhees, C.V. (1996) Stage-specific effects of prenatal d-methamphetamine exposure on behavioral and eye development in rats. Neurotoxicol. Teratol. 18, 199-215.

Asmundson, G. J., Katz, J. (2009) Understanding the co-occurrence of anxiety disorders and chronic pain: state-of-the-art. Depress. Anxiety 26, 888-901.

Belcher, A. M., Feinstein, E. M., O’Dell, S. J., Marshall, J. F. (2008) Methamphetamine influences on recognition memory: comparison of escalating and single-day dosing regimens. Neuropsychopharmacology 33 , 1453-1463.

Belzung, C., Griebel, G. (2001) Measuring normal and pathological anxiety-like behaviour in mice: a review. Behav. Brain Res. 125, 141-149.

Bertoglio, L. J., Carobrez, A. P. (2002) Anxiolytic effects of ethanol and phenobarbital are abolished in test-experienced rats submitted to the elevated plus maze. Pharmacol. Biochem. Behav. 73, 963-969.

Bertoglio, L. J., Anzini, C., Lino-de-Oliveira, C., Carobrez, A. P. (2005) Enhanced dorsolateral periaqueductal gray activity counteracts the anxiolytic response to midazolam on the elevated plus-maze Trial 2 in rats. Behav. Brain Res. 162, 99-107.

Borta, A., Schwarting, R. K. (2005) Inhibitory avoidance, pain reactivity, and plus-maze behavior in Wistar rats with high versus low rearing activity. Physiol. Behav. 84, 387-396.

Bras, M., Dordevic, V., Gregurek, R., Bulajic, M. (2010) Neurobiological and clinical relationship between psychiatric disorders and chronic pain. Psychiatr. Danub. 22, 221-226.

Carobrez, A. P., Bertoglio, L. J. (2005) Ethological and temporal analyses of anxiety-like behavior: the elevated plus-maze model 20 years on. Neurosci. Biobehav. Rev. 29, 1193-1205.

Chen, J.Y., Yeh, G. C., Tao, P. L., Kuo, C. T., Chen, K. B., Wen, Y. R. (2010) Prenatal exposure to methamphetamine alters the mechanical withdrawal threshold and tonic hyperalgesia in the offspring. Neurotoxicology 31, 432-438.

Cornelio, A. M., Nunes-de-Souza, R. L. (2009) Open elevated plus maze-induced antinociception in rats: a non-opioid type of pain inhibition? Physiol. Behav. 96, 440-447.

Fernández Espejo, E. (1997) Structure of the mouse behaviour on the elevated plus-maze test of anxiety. Behav. Brain Res. 86, 105-112.

Fialová, M., Šírová, J., Bubeníková-Valešová, V., Šlamberová, R. (2015) The effect of prenatal methamphetamine exposure on recognition memory in adult rats. Prague Med. Rep. 116, 31-39.

File, S. E. (1993) The interplay of learning and anxiety in the elevated plus-maze. Behav. Brain Res. 58, 199-202.

Geyer, M., Swerdlow, N. R. (2007) Behavioral neuroscience; Rat handling. In: Short Protocols in Neuroscience; Systems and Behavioral Methods. Crawley, J. N., Gerfen, C. R., Rogawski, M. A., Sibley, D. R., Skolnick, P., Wray, S., pp. 89-91, John Wiley and Sons, New Jersey.

Ho, Y. J., Eichendorff, J., Schwarting, R. K. (2002) Individual response profiles of male Wistar rats in animal models for anxiety and depression. Behav. Brain Res. 136, 1-12.

Hrubá, L., Schutová, B., Pometlová, M., Rokyta, R., Šlamberová, R. (2010a) Effect of methamphetamine exposure and cross-fostering on cognitive function in adult male rats. Behav. Brain Res. 208, 63-71.

Hrubá, L., Vaculín, Š., Šlamberová, R. (2010b) Effect of prenatal and postnatal methamphetamine exposure on nociception in adult female rats. Dev. Psychobiol. 52, 71-77.

Jochum, T., Boettger, M. K., Wigger, A., Beiderbeck, D., Neumann, I. D., Landgraf, R., Sauer, H., Bar, K. J. (2007) Decreased sensitivity to thermal pain in rats bred for high anxiety-related behaviour is attenuated by citalopram or diazepam treatment. Behav. Brain Res. 183, 18-24. 
Koga, K., Descalzi, G., Chen, T., Ko, H. G., Lu, J., Li, S., Son, J., Kim, T., Kwak, C., Huganir, R. L., Zhao, M. G., Kaang, B. K., Collingridge, G. L., Zhuo, M. (2015) Coexistence of two forms of LTP in ACC provides a synaptic mechanism for the interactions between anxiety and chronic pain. Neuron 85, 377-389.

Kornetsky, C., Mirsky, A. F., Kessler, E. K., Dorff, J. E. (1959) The effects of dextro-amphetamine on behavioral deficits produced by sleep loss in humans. J. Pharmacol. Exp. Ther. 127, 46-50.

Lautenbacher, S., Krieg, J. C. (1994) Pain perception in psychiatric disorders: a review of the literature. J. Psychiatr. Res. 28, 109-122.

Lee, C., Rodgers, R. J. (1990) Antinociceptive effects of elevated plus-maze exposure: influence of opiate receptor manipulations. Psychopharmacology (Berl.) 102, 507-513.

Marwick, C. (2000) NIDA seeking data on effect of fetal exposure to methamphetamine. JAMA 283 , 2225-2226.

Meredith, C.W., Jaffe, C., Ang-Lee, K., Saxon, A. J. (2005) Implications of chronic methamphetamine use: a literature review. Harv. Rev. Psychiatry 13, 141-154.

Pometlová, M., Deykun, K., Šlamberová, R. (2009) Reliability and validity of anxiety models. Psychiatrie 13, 201-206.

Pometlová, M., Nohejlová-Deykun, K., Šlamberová, R. (2012) Anxiogenic effect of low-dose methamphetamine in the test of elevated plus-maze. Prague Med. Rep. 113, 223-230.

Rambousek, L., Kačer, P., Syslová, K., Bumba, J., Bubeníková-Valešová, V., Šlamberová, R. (2014) Sex differences in methamphetamine pharmacokinetics in adult rats and its transfer to pups through the placental membrane and breast milk. Drug Alcohol Depend. 139, 138-144.

Rodgers, R. J., Cole, J. C. (1994) Pharmacology, methodology and ethology. In: Ethology and Psychopharmacology. Cooper, S. J., Hendrie, C. A., Pp. 9-44, John Wiley and Sons, Chichester.

Rodgers, R. J., Dalvi, A. (1997) Anxiety, defence and the elevated plus-maze. Neurosci. Biobehav. Rev. 21, 801-810.

Rodgers, R. J., Haller, J., Holmes, A., Halasz, J., Walton, T. J., Brain, P. F. (1999) Corticosterone response to the plus-maze: high correlation with risk assessment in rats and mice. Physiol. Behav. 68, 47-53.

Schutová, B., Hrubá, L., Pometlová, M., Deykun, K., Šlamberová, R. (2009) Cognitive functions and drug sensitivity in adult male rats prenatally exposed to methamphetamine. Physiol. Res. 58, 741-750.

Schutová, B., Hrubá, L., Rokyta, R., Šlamberová, R. (2013) Gender differences in behavioral changes elicited by prenatal methamphetamine exposure and application of the same drug in adulthood. Dev. Psychobiol. 55, 232-242.

Simoes, P. F., Silva, A. P., Pereira, F. C., Marques, E., Grade, S., Milhazes, N., Borges, F., Ribeiro, C. F., Macedo, T. R. (2007) Methamphetamine induces alterations on hippocampal NMDA and AMPA receptor subunit levels and impairs spatial working memory. Neuroscience 150, 433-441.

Šlamberová, R., Charousová, P., Pometlová, M. (2005) Methamphetamine administration during gestation impairs maternal behavior. Dev. Psychobiol. 46, 57-65.

Šlamberová, R., Schutová, B., Matějovská, I., Bernášková, K., Rokyta, R. (2009) Effects of a single postnatal methamphetamine administration on NMDA-induced seizures are sex- and prenatal exposure-specific. Naunyn Schmiedebergs Arch. Pharmacol. 380, 109-114.

Šlamberová, R., Mikulecká, A., Pometlová, M., Schutová, B., Hrubá, L., Deykun, K. (2010) The effect of methamphetamine on social interaction of adult male rats. Behav. Brain Res. 214, 423-427.

Šlamberová, R., Vrajová, M., Schutová, B., Mertlová, M., Macúchová, E., Nohejlová, K., Hrubá, L., Puskarčíková, J., Bubeníková-Valešová, V., Yamamotová, A. (2014) Prenatal methamphetamine exposure induces long-lasting alterations in memory and development of NMDA receptors in the hippocampus. Physiol. Res. 63, S547-S558 (Suppl. 4).

Pometlová M.; Yamamotová A.; Nohejlová K.; Šlamberová R. 
Šlamberová, R., Pometlová, M., Macúchová, E., Nohejlová, K., Stuchlík, A., Valeš, K. (2015) Do the effects of prenatal exposure and acute treatment of methamphetamine on anxiety vary depending on the animal model used? Behav. Brain Res. 292, 361-369.

Suer, C., Dolu, N., Ozesmi, C., Sahin, O., Ulgen, A. (1998) The relation between skin conductance level and plus-maze behavior in male mice. Physiol. Behav. 64, 573-576.

Vavř́nková, B., Binder, T., Živný, J. (2001) Characteristics of a population of drug dependent pregnant women in the Czech Republic. Ceska Gynekol. 66, 285-291. (in Czech)

Vrajová, M., Schutová, B., Klaschka, J., Štěpánková, H., Ǩípová, D., Šlamberová, R. (2014) Age-related differences in NMDA receptor subunits of prenatally methamphetamine-exposed male rats. Neurochem. Res. 39, 2040-2046.

Weisenberg, M., Aviram, O., Wolf, Y., Raphaeli, N. (1984) Relevant and irrelevant anxiety in the reaction to pain. Pain 20, 371-383.

Wilson, H. D., Boyette-Davis, J., Fuchs, P. N. (2007) The relationship between basal level of anxiety and the affective response to inflammation. Physiol. Behav. 90, 506-511.

Yamamotová, A., Šlamberová, R. (2012) Behavioral and antinociceptive effects of different psychostimulant drugs in prenatally methamphetamine-exposed rats. Physiol. Res. 61, S139-S147 (Suppl. 2).

Yamamotová, A., Šlamberová, R., Jedlička, M., Jakub, T. (2004) Gender differences in nociception in adult rats prenatally treated with methamphetamine. Homeostasis 43, 99-101.

Yamamotová, A., Pometlová, M., Harmatha, J., Rašková, H., Rokyta, R. (2007) The selective effect of $\mathrm{N}$-feruloylserotonins isolated from Leuzea carthamoides on nociception and anxiety in rats. J. Ethnopharmacol. 112, 368-374.

Yamamotová, A., Hrubá, L., Schutová, B., Rokyta, R., Šlamberová, R. (2011) Perinatal effect of methamphetamine on nociception in adult Wistar rats. Int. J. Dev. Neurosci. 29, 85-92. 